\title{
ANALISISPENGARUH GAYA KEPEMIMPINAN, PELATIHAN DAN DISIPLIN KERJATERHADAP KINERJA KARYAWAN MELALUI KOMPENSASI SEBAGAI VARIABEL INTERVENING (Studi Kasus Pada RSUD Dr. SAIFUL ANWAR Malang)
}

\author{
Fitri Amelia Dwi Astuti \\ Mahasiswa Magister Manajemen Pascasarjana Universitas Islam Malang \\ Email : ameldwi34@gmail.com
}

\begin{abstract}
Abstrak
Tujuan dari penelitian ini adalah untuk menganalisis pengaruh Gaya Kepemimpinan, Pelatihan dan Disiplin Kerja terhadap Kinerja Karyawan melalui Kompensasi sebagai Variabel Intervening. Objek penelitiannya adalah karyawan yang bekerja di salah satu Rumah Sakit Regional milik pemerintah di Jawa Timur. Pengumpulan data dalam penelitian ini menggunakan metode survei menggunakan Kueisioner. Kueisioner dibagikan kepada 180 karyawan di Rumah Sakit Dr. Saiful Anwar Malang yang memiliki kriteria responden sebagai pegawai negeri sipil dan BLUD Non PNS. Ada 17 kue yang tidak terisi dan 13 kue yang tidak terisi sepenuhnya sehingga total 150 kue dapat diproses. Data yang dikumpulkan diproses menggunakan Structure Equition Modeling (SEM) dengan bantuan Perangkat Lunak Pendekatan WarpPLS. Hasil penelitian menunjukkan bukti bahwa Gaya Kepemimpinan, Pelatihan dan Disiplin Kerja masing-masing memiliki hubungan positif dan signifikan dengan Kinerja Karyawan. Ini ditunjukkan oleh hasil analisis di mana setelah diuji dengan konstanta dan Nilai $P$ sesuai dengan masing-masing indikator menghasilkan hasil yang signifikan. Dan selain dari indikator di atas hasil ini juga didukung oleh indikator intervensi, yaitu kompensasi sehingga lebih memperkuat untuk mencapai hasil yang signifikan.

Kata Kunci: Gaya Kepemimpinan, Pelatihan, Disiplin Kerja, Kompensasi dan Kinerja Karyawan
\end{abstract}

\begin{abstract}
The purpose of this study was to analyze the influence of Leadership Style, Training and Work Discipline on Employee Performance through Compensation as an Intervening Variable. The object of his research was employees who worked in one of the government-owned Regional Hospitals in East Java. Data collection in this study uses a survey method using Kueisioner. Kueisioner was distributed to 180 employees at Dr. Hospital Saiful Anwar Malang who has the criteria of respondents as civil servant employees and Non PNS BLUDs. There were 17 nonfilled cakes and 13 cake formers which were not filled completely so that a total of 150 cakes could be processed. The collected data is processed using Structure Equition Modeling (SEM) with the help of WarpPLS Approach Software.

The results of the study show evidence that the Leadership Style, Training and Work Discipline each have a positive and significant relationship to Employee Performance. This is indicated by the results of the analysis where after being tested with constants and $P$ Values according to each indicator it produces significant results. And also aside from the indicators above this result is also supported by intervening indicators, namely compensation so that it is more reinforcing to achieve significant results.
\end{abstract}

Keywords: Leadership Style, Training, Work Discipline, Compensation and Employee Performance. 


\section{PENDAHULUAN}

Peningkatan hasil pelayanan publik dalam bidang jasa yang berkelanjutan menuntut adanya Sumber Daya Manusia (SDM) yang berkinerja tinggi. Karyawan yang memiliki sikap pengabdian, disiplin, dan kemampuan profesional sangat mungkin mempunyai prestasi kerja dalam melaksanakan tugas sehingga lebih berdaya guna dan berhasil guna. Karyawan yang profesional dapat diartikan sebagai sebuah pandangan untuk selalu perpikir, kerja keras, bekerja sepenuh waktu, disiplin, jujur, loyalitas tinggi, dan penuh dedikasi demi untukkeberhasilanpekerjaanya.

Banyak faktor yang mempengaruhi kinerja karyawan, antara lain faktor kepuasan kerja, faktor komunikasi, faktor pengalaman kerja, faktordisiplinkerja, faktor kepemimpinan, faktor kompetensi, faktor pelatihan kerja dan faktor lingkungan kerja. Namun menurut observasi yang dilakukan peneliti berbagai hal permasalahan tersebut ditemukan di lokasi penelitian yaitu di RSUD Dr. Saiful Anwar Malang.Dalam hal ini peneliti ingin mengetengahkan empat faktor yang saling berkaitan, yaitu faktor gaya kepemimpinan,faktorpelatihan, faktor disiplinkerjakaryawan, dan faktor kompensasi. Pemilihan ini didasarkan pada kenyataan bahwa keempat faktor tersebut paling sering muncul dalam teori yang membicarakan faktorfaktor yang berpengaruh terhadap kinerja karyawan.

Proses memotivasi sangat tergantung pada kemampuan pemimpin dan gaya kepemimpinannya untuk mempengaruhi bawahannya dalam upaya untuk mewujudkan tujuan organisasi. Keberhasilan atau kegagalan yang dialami sebagian besar organisasi ditentukan oleh kualitas kepemimpinan yang dimiliki oleh orang-orang yang diserahi tugas memimpin organisasi tersebut. Pelatihan dapat meningkatkan kinerja seorang pegawai baik dalam penanganan pekerjaan yang ada saat ini maupun pekerjaan yang ada pada masa yang akan datang sesuai bidang tugas yang diemban dalam organisasi. Disiplin kerja merupakan bentuk ketaatan dari perilaku seseorang dalam mematuhi ketentuan-ketentuan ataupun peraturan-peraturan tertentu yang berkaitan dengan pekerjaan, dan diberlakukan dalam suatu organisasi. Selain dari faktor kepemimpinan dan disiplin kerja, untuk menciptakan kinerja karyawan yang diharapkan, diperlukan suatu kebijakan yang sesuai (Muslimin, 2007), dan salah satu kebijakan penting yang perlu dikaji adalah pemberian kompensasi yang mampu memotivasi prestasi karyawan (Kismono, 2011). Hasil kerja secara kualitas dan kuantitas yang dicapai oleh seorang pegawai dalam melaksanakan tugasnya sesuai dengan tanggung jawab yang diberikan kepadanya sebagaimana disebut dengan kinerja karyawan (prestasi kerja) juga merupakan salah satu faktor pendorong yang mempengaruhi tingkat disiplin kerja pegawai untuk memberikan kepuasan kepada konsumen di rumah sakit guna menunjang tujuan suatu organisasi.

Penelitian ini mempunyai tujuan untuk: menguji pengaruh AnalisisPengaruh Gaya Kepemimpinan, Pelatihan dan Disiplin Kerja terhadapKinerjaKaryawan melalui Kompensasi sebagai Variabel Intervening. 


\section{KAJIAN TEORI}

Penelitian Wahjosumidjo (1994:21), menyatakan bahwa Kepemimpinan adalah aktivitas para pemegang kekuasaan dan membuat keputusan. Dari pendapat Dubin dapat diartikan bahwa kepemimpinan itu adalah merupakan aktivitas yang dilakukan oleh para pemegang kekuasaan dalam membuat suatu keputusan. Sedangkan menurut House (Yukl, 2009:4), mengatakan bahwa Kepemimpinan adalah kemampuan individu untuk mempengaruhi, memotivasi, dan membuat orang lain mampu memberikan kontribusinya demi efektivitas dan keberhasilan organisasi.

Simamora (1997) menyatakan bahwa pelatihan adalah proses sistematik pengubahan perilaku para karyawan dalam suatu arah guna meningkatkan tujuan organisasional. Dalam pelatihan diciptakan suatu lingkungan dimana para karyawan dapat memperoleh atau mempelajari sikap, kemampuan, keahlian, pengetahuan, dan perilaku yang spesifik yang berkaitan dengan pekerjaan. Pelatihan biasanya terfokus pada penyediaan bagi para karyawan keahlian-keahlian khusus atau membantu mereka mengoreksi kelemahan-kelemahan dalam kinerja mereka.

Disiplin merupakan suatu hal yang sangat penting bagi suatu organisasi atau perusahaan dan mempertahankan atau melangsungkan kehidupannya. Hal ini, disebabkan hanya dengan disiplin yang tinggi suatu organisasi dapat berprestasi tinggi. Hal ini sesuai dengan pendapat Widjaja (1986:29), sebagai berikut: "Dengan perkataan lain disiplin adalah unsur yang penting yangmempengaruhi prestasi dalam organisasi. Tidak ada organisasi yang berprestasi lebih tinggi tanpa melaksanakan disiplin dalam derajat yang lebih tinggi.

Kompensasi merupakan salah satu faktor penting dan menjadi perhatian pada banyak organisasi dalam mempertahankan dan menarik sumber daya manusia yang berkualitas. Kadarisman (2012:1), mengemukakan kompensasi adalah apa yang seseorang karyawan/pegawai/pekerja terima sebagai balasan dari pekerjaan yang diberikannya. Kompensasi yang diberikan organisasi ada yang berbentuk uang, namun ada yang tidak berbentuk uang. Kompensasi yang berwujud upah pada umumnya berbentuk uang, sehingga kemungkinan nilai riilnya turun naik.

Suatu organisasi perusahaan didirikan karena mempunyai tujuan tertentu yang ingin dan harus dicapai. Dalam mencapai tujuannya setiap organisasi di pengaruhi perilaku organisasi. Salah satu kegiatan yang paling lazim di lakukan dalam organisasi adalah kinerja karyawan, yaitu bagaimana ia melakukan segala sesuatu yang berhubungan dengan sesuatu pekerjaan atau peranan dalam organisasi. Sedangkan, menurut Siswanto (2015:11) kinerja ialah prestasi yang dicapai oleh seseorang dalam melaksanakan tugas dan pekerjaan yang diberikan kepadanya. Berdasarkan pemahaman di atas, terlihat bahwa kinerja karyawan adalah perilaku nyata yang ditunjukkan oleh karyawan sebagai hasil kerja yang hasilkan oleh karyawan sesuai dengan perannya di dalam perusahaan. Kinerja karyawan merupakan prestasi kerja atau hasil kerja (output) baik kualitas maupun kuantitas berdasarkan standarkerja yang telah dicapai karyawan per satuan periode waktu dalam melaksanakan tugas kerjanya 
sesuai dengan tanggung jawab yang diberikan kepadanya. Oleh karenanya perusahaan dapat mengetahui perkembangan perusahaannya dengan cara melihat hasil penilaian kinerja karyawan

Berdasarkan argumen di atas maka hipotesis yang akan diuji adalah:

$H_{1}$ : Terdapat pengaruh gaya kepemimpinan terhadap kinerja karyawan di RSUD Dr. Saiful Anwar Malang.

$\mathrm{H}_{2}$ :Terdapat pengaruh pelatihan terhadap kinerja karyawan di RSUD Dr. Saiful Anwar Malang.

$H_{3}$ : Terdapat pengaruh disiplin kerja terhadap kinerja karyawan di RSUD Dr. Saiful Anwar Malang.

$\mathrm{H}_{4}$ : Terdapat pengaruh kompensasi terhadap kinerja karyawan di RSUD Dr. Saiful Anwar Malang.

$\mathrm{H}_{5}$ :Terdapat pengaruh signifikan antara gaya kepemimpinan, terhadap kinerja karyawan dengan kompensasi sebagai variabel intervening.

$H_{6}$ :Terdapat pengaruh signifikan antara pelatihan, terhadap kinerja karyawan dengan kompensasi sebagai variabel intervening

$\mathrm{H}_{7}$ : Terdapat pengaruh signifikan antara disiplin kerja, terhadap kinerja karyawan dengan kompensasi sebagai variabel intervening.

\section{METODE PENELITIAN \\ Populasi dan Sampel}

Populasi yang dipilih dalam penelitian ini adalah karyawan-karyawan yang bekerja tetap di dalam RSUD Dr. Saiful Anwar Malang. Teknik pengambilan sampel dalam penelitian ini adalah menggunakan metode Purposive Sampling dimana Purposive Sampling adalah pemilihan sampel secara tidak acak berdasarkan kriteria tertentu sesuai dengan tujuan penelitian. Sampel yang diambil dalam penelitian ini adalah 180 responden yang terdiri dari pegawai PNS maupun Pegawai BLUD Non PNS yang bekerja di RSUD Dr. Saiful Anwar Malang.

\section{Prosedur Pengumpulan Data}

Sumber data yang digunakan adalah data primer yaitu data yang diperoleh secara langsung baik dari sumber asli (tidak melalui perantara). Data dikumpulkan dengan menggunakan kuesioner kepada para pegawai yang bekerja di RSUD Dr. Saiful Anwar Malang. Dimana kuesioner tersebut diserahkan secara langsung kepada responden dan diambil kembali oleh peneliti setelah kuesioner diisi oleh responden.

\section{Variabel Penelitian Gaya Kepemimpinan}

Gaya Kepemimpinan merupakan energi yang dapat mempengaruhi dan memberi arahan yang terdapat dalam diri seorang pemimpin sehingga dapat mencapai tujuan organisasi. Sedangkan gaya kepemimpinan dapat diartikan sebagai bagaimana seorang karyawan menerima, memahami, terpengaruh, dan memberikan penilaian terhadap kepemimpianan atasan. Gaya kepemimpinan dapat diukur dari empat tipe kepemimpinan, yaitu tipe kepemimpinan direktif, suportif, partisipatif dan kepemimpinan yang berorientasi prestasi dengan menggunakan acuan instrument dari Luthans, 
Fred (2006) dalam skala Likert lima poin, dimana skor terendah (poin 1) menunjukkan partisipasi rendah (sangat tidak setuju), sedangkan skor tertinggi (poin 5) menunjukkan partisipasi tinggi (sangat setuju).

\section{Pelatihan}

Pendidikan dan pelatihan adalah merupakan upaya untuk mengembangkan sumber daya manusia terutama untuk mengembangkan kemampuan intelektual dan kepribadian manusia. Peningkatan, pengembangan dan pembentukan tenaga kerja dilakukan melalui upaya pembinaan, pendidikan, dan pelatihan. Ketiga upaya ini saling terkait, namun pelatihan secara operasional dapat dirumuskan sebagai suatu proses yang meliputi serangkaian tindak (upaya) yang dilaksanakan dengan sengaja dalam bentuk tenaga professional. Pelatihan dalam satuan waktu yang bertujuan untuk meningkatkan kemampuan kerjapeserta dalam bidang pekerjaan tertentu guna meningkatkan efektivitas dan produktivitas dalam suatu organisasi.Pengukuran variable inimenggunakanacuan instrument dari Oemar, $\mathrm{H}$ (2005) dengan menggunakanskala Likert lima poin, dimana skor terendah (poin 1) menunjukkan partisipasi rendah (sangat tidak setuju), sedangkan skor tertinggi (poin 5) menunjukkan partisipasi tinggi (sangat setuju).

\section{Disiplin Kerja}

Disiplin kerja adalah alat yang digunakan manajer untuk berkomunikasi dengan karyawan agar mereka bersedia untuk mengubah suatu perilaku serta sebagai suatu upaya untuk meningkatkan kesadaran dan kesediaan seseorang mentaati semua peraturan perusahaan atau oraganisasi dengan norma-norma sosial yang berlaku. Indikator yang digunaka nuntuk mengukur disiplin kerja adalah kehadiran, ketaatan pada standar kerja, tingkat kewaspadaan tinggi dan bekerja etis yang dikemukakan oleh Rivai (2011) dengan menggunakan skala Likert lima poin, dimana skor terendah (poin 1) menunjukkan partisipasi rendah (sangat tidak setuju), sedangkan skor tertinggi (poin 5) menunjukkan partisipasi tinggi (sangat setuju).

\section{Kompensasi}

Kompensasi yang diberikan organisasi ada yang berbentuk uang, namun ada yang tidak berbentuk uang, sedangkan kompensasi yang berwujud upah pada umumnya berbentuk uang, sehingga kemungkinan nilai riilnya turun naik.Penelitian yang dilakukan oleh Dharmawan (2011) berisi 7 pernyataan, dengan judul "Pengaruh Kompensasi danLingkungan Kerja Non Fisik Terhadap Disiplin dan Kinerja Karyawan Hotel Nikki Denpasar". Indikator yang digunakan dalam peneliatian ini adalah tunjangan, insentif, dan penghargaan. Pengukuran variable ini menggunakan skala Likert lima poin, dimana skor terendah (poin 1) menunjukkan partisipasi rendah (sangat tidak setuju), sedangkan skor tertinggi (poin 5) menunjukkan partisipasi tinggi (sangat setuju).

\section{Kinerja Karyawan}

Kinerja karyawan adalah hasil - hasil fungsi pekerjaan seseorang atau kelompok dalam suatu organisasi pada periode waktu tertentu yang merefleksikan seberapa baik seseorang atau kelompok tersebut memenuhi persyaratan sebuah pekerjan dalam usaha pencapaian tujuan oragnisasi 
Bernardin dan Russell (2002) dengan empat indikator yang meliputi kualitas kerja, kuantitas kerja, pengetahuan, dan kerja sama menggunakan skala Likert lima poin, dimana skor terendah (poin 1) menunjukkan partisipasi rendah (sangat tidak setuju), sedangkan skor tertinggi (poin 5) menunjukkan partisipasi tinggi (sangat setuju).

\section{Teknis Analisis}

Analisis data dalam penelitian ini dilakukan menggunakan Structure Equition Modeling (SEM) dengan menggunakan Pendekatan WarpPLS dengan alasan bahwa SEM memiliki kemampuan untuk menggabungkan pengukuran model (Measurement Model) dengan model struktural (Structural Model) secara simultan dan efisien jika dibandingkan dengan teknik multivariate lainnya (Hair et al., 1998 dalam Ghozali, 2005).

\section{HASIL ANALISIS DATA}

Responden dalam penelitian ini didominasi oleh kaum wanita sebanyak $62,66 \%$ sedangkan kaum pria sebanyak $37,34 \%$. Sebanyak $48 \%$ responden memiliki pendidikan terakhir sebagai D1 atau D3, 27,33\% untuk Sarjana Strata I atau S1, 6,67\% untuk Strata Lanjutan atau biasa dikenal S2 dan sebanyak $18 \%$ untuk pendidikan lain-lain karena dalam faktanya masih dalam proses untuk mengambil pendidikan Sarjana Strata. Dari Tabel 4.2 menunjukkan bahwa dari 150 responden yang diteliti ada 42\% responden yang merupakan Pegawai Negeri Sipil (PNS), dan sebanyak $58 \%$ yang merupakan Pegawai BLUD (Badan Layanan Umum Daerah) Non PNS. Dilihat dari lama proses kinerjanya ada $52 \%$ responden yang merupakan pegawai tetap dan telah bekerja selama 2-5 tahun, 43,33\% pegawai senior yang juga merupakan karyawan tetap dan telah mengabdi lebih dari 5 tahun bekerja, selain itu terdapat pula 4,67\% yang merupakan pegawai baru diangkat menjadi pegawai tetap untuk mengabdi di dalam perusahaan. Sebagai proses untuk menjadi pegawai yang terlatihdan professional dalam bidangnya, padaTabel 4.2 juga ditunjukkan bahwa ada sebanyak $2 \%$ pegawai yang baru mengikuti 1 kali pelatihan, $88 \%$ pegawai yang mengikuti $2-5$ kali pelatihan dan sebanyak $10 \%$ pegawai yang mengikuti pelatihan lebih dari 5 kali dalam kurun waktu 1 tahun, kuesioner yang dapat diolah adalah seperti yang terlihat dalam tabel sebagai berikut:

Tabel 1.1

Karakteristik Responden

\begin{tabular}{|l|c|c|}
\hline Data & Jumlah & Persentase (\%) \\
\hline Jenis Kelamin : & 150 & 100 \\
\hline Pria & 56 & 37,34 \\
\hline Wanita & 94 & 62,66 \\
\hline & & \\
\hline Pendidikan : & 150 & 100 \\
\hline D1/D3 & 72 & 48 \\
\hline S1 & 41 & 27,33 \\
\hline S2 & 10 & 6,67 \\
\hline Lain-lain & 27 & 18 \\
\hline JenisKepegawaian : & 150 & 100 \\
\hline PNS & 63 & 42 \\
\hline BLUD NON PNS & 87 & 58 \\
\hline
\end{tabular}




\begin{tabular}{|l|c|c|} 
& & \\
\hline Lama Bekerja : & 150 & 100 \\
\hline $1 \quad$ tahun & 7 & 4,67 \\
\hline $2-5$ tahun & 78 & 52 \\
\hline$>5$ tahun & 65 & 43,33 \\
\hline & & \\
\hline MengikutiPelatihandalam 1 tahun : & 150 & 100 \\
\hline 1 kali pelatihan & 3 & 88 \\
\hline $2-5$ kali pelatihan & 132 & 10 \\
\hline$>5$ kali pelatihan & 15 & \\
\hline
\end{tabular}

Sumber: Data Primer, diolah.2018

\section{Hasil Uji Asumsi SEM berdasarkan Struktur Equations}

Berdasarkan analisis yang diperoleh dari pengujian yang telah kami lakukan dengan mengunakan Struktur Equations diperoleh tabel sebagai berikut:

Tabel 1.2

Struktur Equations

\begin{tabular}{|c|c|c|c|}
\hline Hubungan Variabel & Konstanta & P Values & Keterangan \\
\hline$\left(X_{1}\right) \longrightarrow \mathrm{Y}$ & 0,27 & $<0,01$ & Signifikan \\
\hline$\left(X_{2}\right) \longrightarrow \mathrm{Y}$ & 0,28 & $<0,01$ & Signifikan \\
\hline$\left(X_{3}\right) \longrightarrow \mathrm{Y}$ & 0,15 & $=0,03$ & Signifikan \\
\hline$\left(X_{4}\right) \longrightarrow \mathrm{Y}$ & 0,11 & $=0,08$ & Signifikan \\
\hline$\left(X_{1}\right) \rightarrow\left(X_{4}\right) \rightarrow Y$ & 0,19 & $<0,01$ & Signifikan \\
\hline$\left(X_{2}\right) \rightarrow\left(X_{4}\right) \rightarrow Y$ & 0,21 & $<0,01$ & Signifikan \\
\hline$\left(X_{3}\right) \rightarrow\left(X_{4}\right) \rightarrow Y$ & 0,13 & $=0,05$ & Signifikan \\
\hline
\end{tabular}

Sumber: Data Primer, diolah.2018 


\section{PEMBAHASAN}

Berdasarkan kerangka konseptual dalam penelitian ini, berikut disajikan model atau diagram alur (path diagram), yaitu:

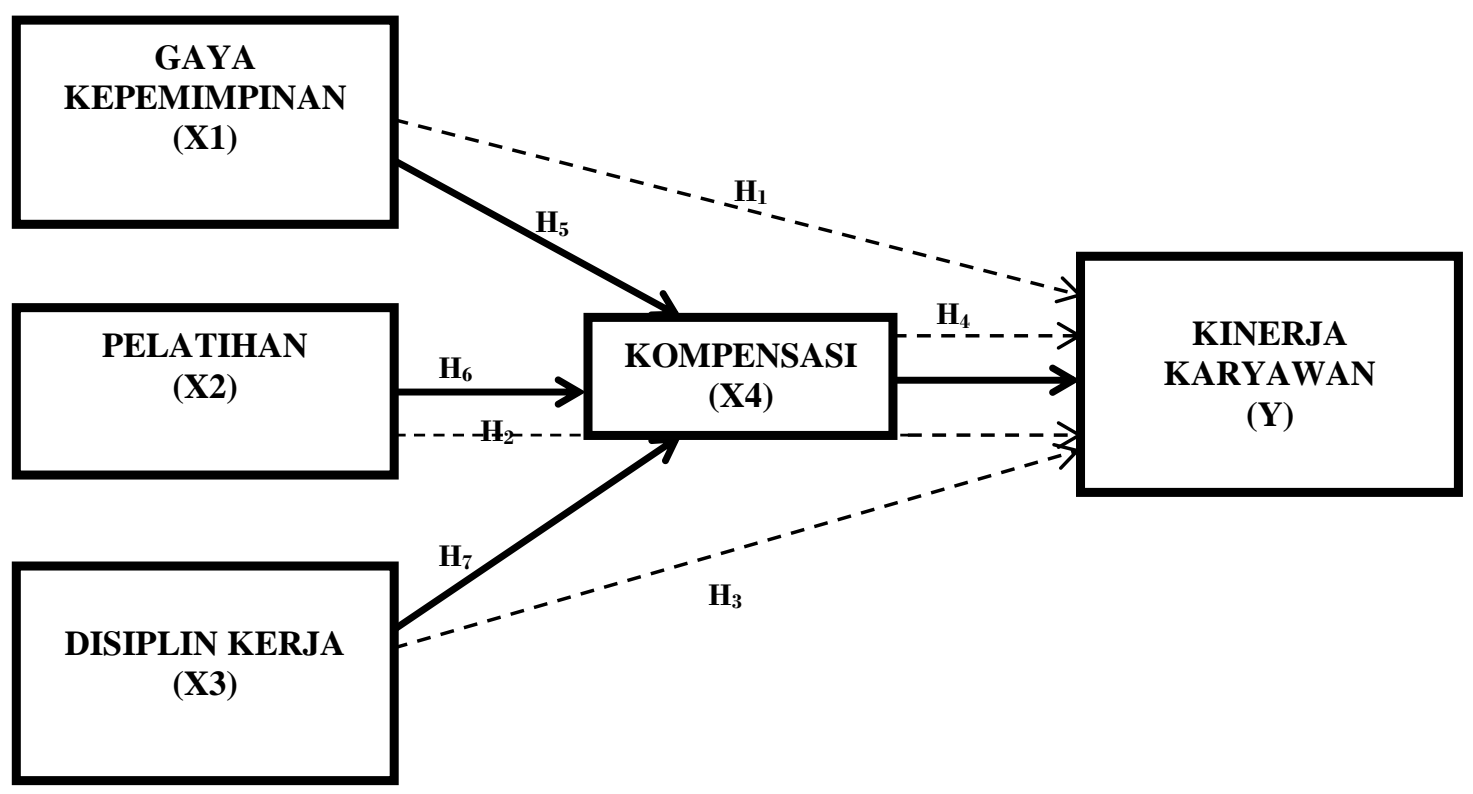

\section{Gambar 1.1 \\ Model Penelitian \\ Structural Equation Modeling (SEM) \\ Kovarians Antar Variabel}

Dengan variabel eksogen yaitu Gaya Kepemimpinan $\left(X_{1}\right)$, Pelatihan $\left(X_{2}\right)$, Disiplin Kerja $\left(X_{3}\right)$ dan Kompensasi $\left(X_{4}\right)$ serta variabel endogen yaitu Kinerja Pegawai (Y), maka setelah model disajikan secara lengkap, selanjutnya adalah memilih jenis input yang sesuai. Menurut Hair, dkk (1995) dalam Ferdinand (2000), bila yang diuji adalah hubungan kausalitas, maka disarankan input yang digunakan adalah covariance.

Dari penelitian yang telah dilakukan berikut ini data kovarians yang digunakan yaitu:

Tabel 5.1

Path Coefficients and P-value

Part Coefficiens

\begin{tabular}{|c|c|c|c|c|c|}
\hline & $\mathrm{X} 1$ & $\mathrm{X} 2$ & $\mathrm{X} 3$ & X4 & Y \\
\hline \multicolumn{6}{|l|}{$\mathrm{X} 1$} \\
\hline \multicolumn{6}{|l|}{$\mathrm{X} 2$} \\
\hline \multicolumn{6}{|l|}{ X3 } \\
\hline X4 & 0.194 & -0.212 & 0.131 & & \\
\hline$Y$ & 0.266 & 0.275 & 0.151 & 0.114 & \\
\hline \multicolumn{6}{|l|}{$P$-value } \\
\hline & $\mathrm{X} 1$ & X2 & X3 & X4 & Y \\
\hline
\end{tabular}




\begin{tabular}{|c|c|c|c|c|}
\hline X1 & & & & \\
\hline $\mathrm{X} 2$ & & & & \\
\hline X3 & & & & \\
\hline X4 & 0.007 & 0.004 & 0.050 & \\
\hline $\mathrm{Y}$ & $<0.001$ & $<0.001$ & 0.029 & 0.076 \\
\hline
\end{tabular}

Sumber: Data Primer, diolah. 2018.

Dari tabel 5.1 di atas Dari table diatas dapat dilihat bahwa kolom laten predictor dan baris menunjukkan variable laten criterion. Dari table diatas dapat dijelaskan bahwa koefisien Gaya Kepemimpinan (X1) terhadap Kompensasi (X4) ini signifikan dan berpengaruh positif dikarenakan p-value sebesar 0,194 (<0.05). Sehingga dapat di interpretasikan bahwa semakin besar koefisien jalur berarti pengaruhnya semakin kuat, seperti pada $X 1$ terhadap $Y$ dengan koefisien jalur 0,266 (signifikan dengan $p<0.001$ ), begitu juga dengan $X 2$ terhadap $X 4$ dengan koefisien $\quad-0.212$ dan $X 2$ terhadap $Y$ dengan koefisien 0,275 (signifikan dengan $p<0,001$ ). Dalam hal ini $X 3$ terhadap $X 4$ dengan nilai koefisien 0,131 (signifikan dengan $p=0,05$ ) dan $X 3$ terhadap $Y$ dengan nilai koefisien 0,151 dengan nilai koefisien 0,151 (signifikan dengan $p=0,03$ ). Tetapi untuk $X 4$ terhadap $Y$ memiliki pengaruh kuat dengan nilai koefisien 0,076 (dimana signifikan dengan $\mathrm{p}=0,08$ ).

\section{Tabel 5.2}

\section{Standard Errors For Path Coefficient}

\begin{tabular}{|c|r|r|r|r|r|}
\hline & $\mathrm{X} 1$ & $\mathrm{X} 2$ & $\mathrm{X} 3$ & $\mathrm{X} 4$ & $\mathrm{Y}$ \\
\hline $\mathrm{X} 1$ & & & & & \\
\hline $\mathrm{X} 2$ & & & & & \\
\hline $\mathrm{X} 3$ & & & & & \\
\hline $\mathrm{X} 4$ & 0.078 & 0.078 & 0.079 & & \\
\hline $\mathrm{Y}$ & 0.078 & 0.078 & 0.079 & 0.080 & \\
\hline
\end{tabular}

Sumber: data primer diolah(Desember 2018)

Dari table diatas sebagai mediasi hubungan linier. Selain itu juga berguna untuk menguji efek mediasi hubungan non linier.

Tabel 5.3

Effect size for path coefficient

\begin{tabular}{|c|r|r|r|r|r|}
\hline & \multicolumn{1}{|c|}{$\mathrm{X} 1$} & $\mathrm{X} 2$ & $\mathrm{X} 3$ & $\mathrm{X} 4$ & $\mathrm{Y}$ \\
\hline $\mathrm{X} 1$ & & & & & \\
\hline $\mathrm{X} 2$ & & & & & \\
\hline $\mathrm{X} 3$ & & & & & \\
\hline $\mathrm{X} 4$ & 0.026 & 0.031 & 0.017 & & \\
\hline $\mathrm{Y}$ & 0.107 & 0.104 & 0.042 & 0.016 & \\
\hline
\end{tabular}

Sumber: data primer diolah(Desember 2018) 
Dari table effect size ditunjukkan pengaruh Gaya Kepepmimpinan (X1) terhadap Kompensasi (X2) dan pengaruh Gaya Kepemimpinan (X1) terhadap Kinerja Karyawan $(Y)$. Kemudian Pelatihan (X2) mempengaruhi Kompensasi (X4) dan berpengaruh juga terhadap Kinerja Karyawan (Y). Kemudian Untuk Pelatihan (X3) berpengaruh terhadap Kompensasi (X4) dan juga berpengaruh terhadap Kinerja Karyawan (Y).

Tabel 5.4

\section{Laten Variable Coefficient}

\begin{tabular}{|c|c|c|c|c|c|}
\hline & \multicolumn{1}{|c|}{ X1 } & \multicolumn{1}{|c|}{ X2 } & \multicolumn{1}{c|}{ X3 } & \multicolumn{1}{c|}{ X4 } & Y \\
\hline R-squared & & & & 0.074 & 0.269 \\
\hline Adj.R-squared & & & & 0.055 & 0.249 \\
\hline Composite Reliable & 0.841 & 0.825 & 0.772 & 0.918 & 0.896 \\
\hline Cronbach's extrac & 0.798 & 0.764 & 0.668 & 0.892 & 0.872 \\
\hline Avg.var.extrac & 0.266 & 0.331 & 0.321 & 0.624 & 0.426 \\
\hline Full Collin.VIF & 1.279 & 1.259 & 1.076 & 1.064 & 1.335 \\
\hline Q-squared & & & & 0.085 & 0.278 \\
\hline Min & -3.295 & -3.090 & -2.658 & -3.519 & -2.472 \\
\hline Max & 2.255 & 2.203 & 2.180 & 1.923 & 1.841 \\
\hline Median & -0.094 & -0.118 & -0.235 & 0.312 & -0.120 \\
\hline Mode & -0.133 & -0.118 & -0.335 & 0.312 & -0.500 \\
\hline Skewness & 0.005 & -0.094 & -0.004 & -0.595 & 0.050 \\
\hline Exc.kurtosis & -0.138 & 0.766 & -0.021 & 1.026 & -0.452 \\
\hline Unimodal-RS & Yes & Yes & Yes & Yes & Yes \\
\hline Unimodal-KMV & Yes & Yes & Yes & Yes & Yes \\
\hline Normal -JB & Yes & Yes & Yes & No & Yes \\
\hline Normal-RJB & Yes & No & Yes & No & Yes \\
\hline Histogram & View & View & View & View & View \\
\hline Sumber: dataprmer dion & & & & \\
\hline
\end{tabular}

Sumber: data primer diolah(Desember 2018)

Berdasarkan hasil ouput diatas diperoleh nilai R-squared untuk pelaksanaan Kinerja Karyawan ( $\mathrm{Y}$ ) sebesar 0,269 yang memiliki arti bahwa pengaruh Gaya Kepemimpinan (X1) memediasi Pelatihan (X2) dan Disiplin Kerja (X3) serta Kompensasi (X4) dalam Kinerja Karyawan (Y) yaitu sebesar $27 \%$ dan sisanya $73 \%$ dipengaruhi oleh variabel lain diluar model penelitian ini. Kemudian diperoleh $\mathrm{R}$-squared untuk variabel Kompensasi sebesar 0,074 yang memiliki arti bahwa kompensasi memediasi gaya kepemimpinan, pelatihan dan disiplin kerja juga kinerja karyawan sebesar $0,074 \%$ dan sisanya $99,926 \%$ dipengaruhi oleh variabel lain. 
Berdasarkan hasil output diatas bahwa composite reliability dan cronbach's alphad semua vareabel bernilai, sehingga dapat dinyatakan semua variabel penelitian ini telah memenuhi syarat reabilitas.

\section{SIMPULAN DAN SARAN}

Berdasarkan hasil penelitian dan pembahasan mengenai analisis Pengaruh Gaya Kepemimpinan, Pelatihan, dan Disiplin Kerja terhadap Kinerja Karyawan melalui Kompensasi sebagai Variabel Intervening Studi Kasus di RSUD Dr. Saiful Anwar Malang, maka dapat ditarik simpulan sebagai berikut:

a. Adanya pengaruh signifikan antara gaya kepemimpinan terhadap kinerja karyawan di RSUD Dr. Saiful Anwar Malang.

b. Adanya pengaruh signifikan antara pelatihan terhadap kinerja karyawan di RSUD Dr. Saiful Anwar Malang.

c. Adanya pengaruh signifikan antara disiplin terhadap kinerja karyawan di RSUD Dr. Saiful Anwar Malang.

d. Adanya pengaruh signifikan antara kompensasi terhadap kinerja karyawan di RSUD Dr. Saiful Anwar Malang.

e. Adanya pengaruh signifikan antara gaya kepemimpinan terhadap kinerja karyawan di RSUD Dr. Saiful Anwar Malang dengan kompensasi sebagai variabel intervening.

f. Adanya pengaruh signifikan antara pelatihan terhadap kinerja karyawan di RSUD Dr. Saiful Anwar Malang dengan kompensasi sebagai variabel intervening.

g. Adanya pengaruh signifikan disiplin kerja terhadap kinerja karyawan di RSUD Dr. Saiful Anwar Malang dengan kompensasi sebagai variabel intervening.

\section{DAFTAR PUSTAKA}

Amri, Khaerul., 2015, Pengaruh Kepemimpinan, Motivasi, Disiplin Kerja, dan Pelatihan Kerja terhadap Kinerja Karyawan BMT Bina Ishanul Fikri Yogyakarta. Skripsi. Fakultas Syariah dan Hukum, Universitas Kalijaga. Yogyakarta.

Arikunto, Suharsini., 2006. "Prosedur Penelitian: Suatu Pendekatan Praktek”. Rineka Cipta. Jakarta.

Erick P., Guido., 2016, Pengaruh Persepsi Gaji dan Motivasi terhadap Kinerja Karyawan. Sripsi. Fakultas Ekonomi, Universitas Sanata Dharma. Yogyakarta.

Evanita, Leny,. 2013, Disiplin Kerja, Gaya Kepemimpinan, Pelatihan dan Kinerja Karyawan di RSUD Lubuk Sikaping Pasaman. Tesis. Program Pasca Sarjana. Universitas Esa Unggul. Jakarta.

Ferdinand, Agusty. 2000. "Structural Equation Modeling dalam Penelitian Manajemen". Semarang : Badan Penerbit UNDIP.

Hasibuan, Malayu Sp., 2006. Manajemen Sumber Daya Manusia. Jakarta : Bumi Aksara.

Indriantoro, Nurdan Bambang Supomo. 2002. Metode Penelitian Bisnisuntuk Akuntansi dan Manajemen, Yogyakarta : Penerbit BPFE. 
Kurniadi, Fajar. (2012), Pengaruh Kompensasi dan Motivasi Kerja Karyawan di Apotek Berkah.Skripsi, Fakultas Bisnis dan Manajemen Universitas Widyatama.

Luthands, Fred., 2006. Perilaku Organisasi. Jilid 10, Yogyakarta. ANDI, h. 557

M. Harlie, "Pengaruh Disiplin Kerja, Motivasi dan Pengembangan Karier terhadap Kinerja Pegawai Negeri Sipil pada Pemerintah Kabupaten Tabalong di Tanjung Kalimantan Selatan", Jurnal Manajemen Sekolah Tinggi Ilmu Administrasi Tabalong, 2010.

Oemar, H., 2005. Pengembangan Sumber Daya Manusia: Manajemen Pelatihan Ketenagakerjaan (Pendekatan Terpaadu). Jakarta : Bumi Aksara, h. 10.

Pradipto, Sindu., 2015, Analisis Pengaruh Gaya Kepemimpinan dan Disiplin Kerja terhadap Kinerja Pegawai dengan Motivasi Kerja sebagai Variabel Intervening. Skripsi. Fakultas Ekonomika dan Bisnis, Universitas Diponegoro. Semarang.

Purwanto dan Suharyadi. 2004. "Statistika untuk Ekonomi dan Keuangan Modern". Salemba Empat : Jakarta.

Rivai, Veithzal., 2004. Manajemen Sumber Daya Manusia Untuk Perusahaan. Jakarta : Muri Kencana.

Rafi, Jody., 2016, Pengaruh Kompensasi dan Motivasi Kerja terhadap Kinerja Karyawan Rumah Sakit Condong Catur Yogyakarta. Skripsi. Fakultas Ekonomi, Universitas Negeri Yogyakarta.

Rivai, Veithzal dan Sagala, Ella Jauvani. (2004). Manajemen Sumber Daya Manusia untuk Perusahaan dari Teori ke Praktek. Jakarta: PT. Raja Grafindo Persada.

Sekaran, Uma \& Roger Bougie., 2009. Research Methods for Business: A Skill Building Approach. United Kingdom : John Wiley \& Sons Ltd.

Siagian, Sondang P., 2004. Manajemen Sumber Daya Manusia. Jakarta: Salemba Empat.

Simamora, Henry. (2009). Manajemen Sumber Daya Manusia. STIE YKPN Yogyakarta.

Sudarmanto, 2009. Kinerja dan Pengembangan Kompetensi SDM Teori, Dimensi dan Implementasi dalam Organisasi. Yogyakarta : Pustaka Pelajar.

Teguh, Sabdo., 2016, Pengaruh Gaya Kepemimpinan dan Disiplin Kerja Terhadap Kinerja Pegawai Perum Perhutani KPH Kedu Utara. Skripsi. Fakultas Ekonomi, Universitas Negeri. Yogyakarta

Wahjosumidjo, (1994:21). Kepemimpinan dan Motivasi. Ghalia Indonesia : Jakarta.

Wibowo, Manajemen Kinerja, edisi ke-3, Jakarta: Rajawali Pers, 2010.

Yukl, Gary. (2009:4). Kepemimpinan Dalam Organisasi, Edisi Kelima. Jakarta : PT Indeks.

Website: http://www.info.saifulanwar@gmail.com https://rsusaifulanwar.jatimprov.go.id/ 